\title{
A validation of well-being and happiness surveys for administration via the Internet
}

\author{
Ryan T. Howell \\ San Francisco State University, San Francisco, California \\ Katrina S. Rodzon \\ Utah State University, Logan, Utah \\ AND \\ Mark Kurai And Amy H. SAnchez \\ San Francisco State University, San Francisco, California
}

\begin{abstract}
Internet research is appealing because it is a cost- and time-efficient way to access a large number of participants; however, the validity of Internet research for important subjective well-being (SWB) surveys has not been adequately assessed. The goal of the present study was to validate the Satisfaction With Life Scale (SWLS; Diener, Emmons, Larsen, \& Griffin, 1985), the Positive and Negative Affect Schedule (PANAS-X; Watson \& Clark, 1994), and the Subjective Happiness Scale (SHS; Lyubomirsky \& Lepper, 1999) for use on the Internet. This study compared the quality of data collected using paper-based (paper-and-pencil version in a lab setting), computer-based (Web-based version in a lab setting), and Internet (Web-based version on a computer of the participant's choosing) surveys for these three measures of SWB. The paper-based and computer-based experiment recruited two college student samples; the Internet experiments recruited a college student sample and an adult sample responding to ads on different social-networking Web sites. This study provides support for the reliability, validity, and generalizability of the Internet format of the SWLS, PANAS-X, and SHS. Across the three experiments, the results indicate that the computer-based and Internet surveys had means, standard deviations, reliabilities, and factor structures that were similar to those of the paper-based versions. The discussion examines the difficulty of higher attrition for the Internet version, the need to examine reverse-coded items in the future, and the possibility that unhappy individuals are more likely to participate in Internet surveys of SWB.
\end{abstract}

Advances in Web technology and widespread use of the Internet have provided survey researchers with an inexpensive and efficient method of accessing a vast participant pool and the ability to target specific populations that might otherwise be difficult to locate. Buchanan and Smith (1999) argued that online or Internet surveys might have better psychometric properties than do identical paper-and-pencil (PP) or computer-based (CB) surveys. Past research has shown that those taking Internet surveys provide longer, more detailed answers to open-ended questions than do those taking PP surveys (Denscombe, 2008). To date, there have been numerous studies examining the equivalence of PP, CB, and Internet surveys. For the most part, past research has shown that the results from PP, CB, and Internet surveys are similar. For example, past research has demonstrated the comparability of PP, CB, and Internet personality surveys (Birnbaum, 2004; Bliven, Kaufman, \& Spertus, 2001; Buchanan \& Smith, 1999; Chuah, Drasgow, \& Roberts, 2006; Gosling, Vazire, Srivastava, \& John, 2004; Reimers \& Stewart, 2007; Riva, Teruzzi, \& Anolli, 2003; Williams, McGraw,
$\&$ Tew, 1999). Further support for the comparability between PP, CB, and Internet-administered surveys has been demonstrated in several areas, including methodology (Birnbaum, 2004; Gosling et al., 2004; McGraw, Tew, \& Williams, 2000; Riva et al., 2003), health (Bliven et al., 2001), training (Luthans, Avey, \& Patera, 2008), transformational leadership (Cole, Bedeian, \& Field, 2006), associative learning (Vadillo, Bárcena, \& Matute, 2006), and reaction time (Reimers \& Stewart, 2007).

Although the Internet presents many benefits to survey methodology (Gosling et al., 2004), an equivalent response across survey methods does not necessarily indicate that the samples are interchangeable. For example, whereas the Internet might provide access to a more diverse sample, Internet surveys may be biased toward participants who are young, educated, and of middle to high socioeconomic status. Internet samples might be volunteering solely out of curiosity or interest in the research topic, compared with those recruited by traditional methods who might be motivated by course credit or other compensation. Furthermore, the environmental and physi-

R.T. Howell, rhowell@sfsu.edu 
cal conditions under which Internet surveys are completed are uncontrolled and are unknown to the researchers. Bech and Kristensen (2009) noted that although online surveys may have cost, time, and effort advantages over PP surveys, online surveys with lower response rates are prone to a nonresponse bias.

All these concerns threaten the quality and validity of any online version of a PP survey and suggest that all surveys need to be validated for use on the Internet. Specifically, Buchanan and Smith (1999) questioned whether the results of any PP or CB versus Internet survey would generalize to all questionnaires, and they warned that Internet recruiting strategies could have a large impact on any online study. More recently, Fortson, Scotti, Del Ben, and Chen (2006; see also Lonsdale, Hodge, \& Rose, 2006) suggested that researchers must be cautious not to overgeneralize findings from PP or CB versus Internet comparisons and that they must be aware that certain populations (e.g., clinical populations) may behave differently. Finally, very few studies have attempted to validate many of the most important measures of subjective well-being (SWB). Thus, the aim of the present study was to validate three of the most widely used SWB measures for data collection via the Internet. In particular, we addressed two general concerns: the inconsistency of equivalence across surveys, and the possible difference in disclosure of personal information.

\section{Possible Differences in PP, CB, and Internet Surveys}

Factor structure. Although past work has demonstrated that $\mathrm{CB}$ and Internet data are comparable to PP data (Birnbaum, 2004; Bliven et al., 2001; Buchanan \& Smith, 1999; Gosling et al., 2004; Reimers \& Stewart, 2007; Riva et al., 2003; Williams et al., 1999), the factor structure of surveys administered using PP, CB, and Internet methods have been varied. Buchanan and Smith demonstrated that the correlation of how items loaded on the Self-Monitoring Scale was high $(r=.89)$ between an Internet sample (recruited by means of messages posted to Usenet newsgroups) and published norms. Randomly assigning a participant to receive either a PP or an online survey via a URL link in an e-mail, Lonsdale et al. (2006) demonstrated that there was no significant difference between groups in the alpha coefficients, factorial structure, or latent means for any subscale on the Athlete Burnout Questionnaire. They also reported that there were no significant differences between response rates, although there was less of a time lag for the online survey.

Other studies have provided evidence that PP and Internet methods yield inconsistent factor structures $(\mathrm{Bu}-$ chanan, 2002; Buchanan, Johnson, \& Goldberg, 2005). Hewson and Charlton (2005) assessed the factor structure and reliability for the Multidimensional Health Locus of Control Scale and demonstrated that the fit indices calculated for the online (recruited from a variety of newsgroups) and PP samples sometimes indicated that the Internet sample had a better fit and at other times that the PP sample had a better fit, depending on the index used.
Using the International Personality Item Pool, Buchanan et al. reported two questions that loaded onto the "wrong" factor-(1) I make people feel at ease, and (2) I carry the conversation to a higher level - and as a result dropped these items from the analyses. To evaluate the predictive validity of Goldberg's personality measure across different media, Chuah et al. (2006) had to drop two items from the neuroticism scale (i.e., emotional and fretful) to make the measure unidimensional.

These findings suggest that constructs measured using Internet surveys may not have the same factor structure as those measured using PP or CB surveys. If there are differences in factor structure, resulting in dropping items when data are collected over the Internet, then studies that collect data over the Internet are likely to create constructs that are not equivalent to those of the original PP versions. Any differences in the factor structure of wellbeing measures for Internet data has the potential to skew or influence the models created using these constructsultimately creating a situation in which PP and Internet studies are not comparable; therefore, the present study evaluated the possible impact of PP and CB versus Internet administration on the factor structure of important SWB variables.

Self-disclosure. One of the major concerns raised by researchers is that the responses on PP surveys will differ from the responses on online surveys because the anonymity of the Internet might lead to disinhibition (Fortson et al., 2006; Joinson, 1999). This would be a particular concern for SWB data collected over the Internet because of the sensitive nature of SWB and the need to assess typical emotional states to form constructs of SWB. Past research (Joinson, 1999) has shown that respondents to an online survey scored higher on self-esteem, lower on social anxiety, and lower on social desirability. When examining self-disclosed information, participants are more likely to divulge personal or private information (e.g., negative affect, suicidal tendencies) on online surveys than on PP or CB surveys (Buchanan, 2002; Davis, 1999). Carlbring et al. (2007) demonstrated that respondents reported higher levels of depression when completing a CB survey than when completing a PP survey. In addition, differences have been found for disclosure of personal information and social desirability for online surveys (Buchanan, 2002; Davis, 1999; Shih \& Fan, 2008) —with increased honesty observed when the surveys were administered through the Internet.

Conversely, many studies have demonstrated the opposite effect. Vereecken and Maes (2006) showed that participants provided more socially desirable information regarding their emotional state when data were collected with a PP survey. Rosenfeld et al. (1991) hypothesized that individuals who scored high on self-monitoring would report higher job satisfaction when completing a PP survey and would also report lower job satisfaction on Internet surveys. The results were the exact opposite: Employees who were higher in self-monitoring reported less job satisfaction on the PP survey. Finally, Fortson et al. (2006) showed that although the reporting of traumatic events 
increased when participants completed an online survey a week after completing a PP survey, this finding did not occur for the other measures. They concluded that their results did not support the hypothesis that taking the survey online would produce disinhibition, as had been shown in previous research. Thus, there are possible inconsistencies when comparing Internet surveys with PP methods that result from specific types of constructs, different sampling procedures, or varying degrees of susceptibility to disinhibition in respondents. The present study tested to see whether SWB measures (specifically, reports of negative emotions) were altered when participants completed Internet-based surveys.

\section{Validating SWB Measures for Use on the Internet}

Well-being on an individual level has been variously defined in terms of affective, cognitive, and psychological processes. Previous assessments of individual wellbeing have focused primarily on self-evaluative measures of mood, positive and negative affect, life satisfaction, and quality of life. Such evaluations define the construct of SWB. Diener and Seligman (2004) noted that SWB includes the positive evaluations individuals make about their lives. Ryan and Deci (2001) defined SWB as the trifold components of (1) life satisfaction, (2) presence of positive mood, and (3) absence of negative mood. Given the rise in the number of studies measuring and understanding high SWB, the increased use of the Internet to collect SWB data, and the necessity for all surveys to be validated for use on the Internet, it is essential to validate measures of SWB for Internet use.

Most research that has examined the equivalence of measurements of well-being across PP, CB, and Internet surveys has focused on negative emotions or affect, stress, and depression. These studies have reported divergent findings. $\mathrm{Yu}$ and $\mathrm{Yu}$ (2007) demonstrated that when teachers in Taiwan completed an online survey containing the Chinese version of the Center for Epidemiologic Studies Depression Scale (CES-D) or completed a PP CES-D that was administered through the mail, there was no difference in reliability or factor structures, and very little difference in latent means, when comparing the two groups. Herrero and Meneses (2006) randomly assigned college students to complete two brief measures of depression and stress (the Perceived Stress Scale and the CES-D) as either a PP or an Internet survey. They found no difference in reliability or factor structures and argued that the two surveys were equivalent. Im et al. (2005) recruited 77 women to complete a PP Midlife Women's Symptom Index (MSI) survey; 81 women were recruited via Internet groups and fliers to take the Internet-based MSI survey. Their results supported the reliability and validity of the online MSI.

Contrary to the above findings, George, Lankford, and Wilson (1992) and Tseng, Macleod, and Wright (1997) both reported that individuals with computer anxiety experienced increased negative emotions when using computerized personality testing. Vallejo, Mañanes, Comeche, and Díaz (2007) recruited 40 demographically similar university students and randomly assigned them to either an Internet-paper sequence or a paper-Internet sequence. The participants completed the Spanish adaptation of the Symptom Check List and the General Health Questionnaire and then returned a week later to complete the questionnaires in the other sequence. The researchers found that some of the subscales had significantly different scores between formats, depending on the sequence, and that the paper version was viewed as more pleasant than was the online version when taken after the online version.

As noted previously, SWB is constructed of multiple facets, most of which are positive (e.g., life satisfaction, quality of life, and psychological need satisfaction). A review of the literature found a single study (Květon, Jelínek, Klimusová, \& Vobořil, 2007) that attempted to validate the Satisfaction With Life Scale (SWLS; Diener, Emmons, Larsen, \& Griffin, 1985), and no study that has attempted to validate the Positive and Negative Affect Schedule (PANAS-X; Watson \& Clark, 1994) or the Subjective Happiness Scale (SHS; Lyubomirsky \& Lepper, 1999). Using a sample of 130 university students, Květon et al. examined differences in the SWLS. They found that an Internet version of the SWLS did not differ from the PP version when comparing the means, variances, reliabilities, and correlations to extraversion and happiness. Although Květon et al. did provide evidence that the SWLS and the Oxford Happiness Questionnaire were valid surveys to administer through the Internet, there were some limitations to their study. First, the authors recruited only college students and did not use any Internet sampling procedures. Second, the authors did not administer any of their surveys using a CB method. Third, they did not compare the factor structure of the scales across conditions. Our study attempted to replicate and extend their finding regarding the SWLS as well as to test the validity of the PANAS-X and the SHS for Internet delivery.

\section{The Present Study}

The present study extends previous research in Internet-based survey methodology by focusing specifically on measurements of SWB to assess whether Internet-administered surveys are comparable to PP and CB surveys in (1) factor structure, (2) reliability, (3) validity, and (4) generalizability. In order to accomplish these goals, we (1) tested for equivalence of factor structures (following the guidelines of Tabachnick \& Fidell [1989]), (2) compared the internal consistency across conditions, (3) evaluated the predictive relationships of different SWB outcomes, and (4) examined the factor structure, internal consistency, and correlational patterns between students from San Francisco State University (SFSU) and adults recruited from different social-networking Web sites. Thus, the major objectives of this study were to determine the robustness of disparate well-being scales in terms of their factor structure and internal consistency when administered in a lab setting as a PP or CB survey versus through the Internet. A secondary objective was to determine the sampling characteristics of individuals who completed SWB scales re- 
cruited through social-networking sites (e.g., Craigslist and Facebook).

\section{METHOD}

To determine the robustness of SWB scales, we collected survey data using three different experiment designs. Experiment $1 \mathrm{col}-$ lected data using both an Internet survey and a CB lab survey; Experiment 2 collected data using both an Internet survey and a paperformatted lab survey; and Experiment 3 collected two samples of Internet data (a college student sample and an adult sample responding to ads on different social-networking Web sites). Because we attempted to minimize the time commitment for participants in Experiments 1 and 2, those experiments did not include all measures we were attempting to validate.

\section{Procedure and Participants}

In Experiment 1, participants were randomly assigned to either complete a survey on a computer in a lab setting (the $C B$ condition) or complete an identically formatted survey at a computer of their choice (the Internet condition). Participants assigned to the $\mathrm{CB}$ condition were required to sign up for a time to come into a lab at SFSU and complete the computer-formatted questionnaire. All other participants completed an identical questionnaire via the Internet at a time of their choosing. The survey consisted of (1) the SWLS (Diener et al., 1985), (2) the PANAS-X (Watson \& Clark, 1994), and (3) the Big Five Inventory (BFI; John, Donahue, \& Kentle, 1991). Although the BFI has been validated for Internet use (see Buchanan et al., 2005), to assess the validity of the SWLS and the PANAS-X when administered as an Internet survey versus in a CB format, we tested for differences in correlational patterns across the two conditions. Participants were 199 undergraduate students at SFSU participating for course credit. The participants were of average college age $(M=21.81$ years, $S D=5.80)$, with more females $(84 \%)$ participating than males. There was racial diversity in the sample, with $38 \%$ reporting themselves as being European American/White, 26.5\% as Asian American/Asian, $12.2 \%$ as Latino American/Latino, $8.7 \%$ as African American, $1 \%$ as Arab American/Arab, and 13.3\% as "other." Both conditions displayed similar characteristics across age, gender, and ethnicity composition.

In Experiment 2, participants completed either a PP or an Internet-formatted survey. Participants during the first week of the experiment completed the PP survey in a lab setting $(n=95)$; participants during the second week of the experiment completed the Internet survey $(n=78)$. To complete the PP condition, the participants were scheduled to take the test in a lab setting at a scheduled time. Participants in the Internet condition took the survey at a computer of their choosing and at their own time. The survey consisted of the SWLS and the SHS (Lyubomirsky \& Lepper, 1999). A total of 173 SFSU students were recruited from the Psychology Department for participation, and they were compensated with course credit. Participants were older than average college age ( $M=24.41$ years, $S D=5.46)$, with more females $(73 \%)$ participating than males. There was racial diversity in the sample, with $34.1 \%$ reporting themselves as being Caucasian, $25.4 \%$ as Asian American, $15.0 \%$ as Hispanic, $12.1 \%$ as multiracial, $3.5 \%$ as African American, $5.2 \%$ as South Asian/Indian subcontinent, and 2.9\% as "other." Both conditions displayed similar characteristics across age, gender, and ethnicity composition.

In Experiment 3, in which all participants completed an Internetbased survey, participants were recruited from either SFSU $(n=$ $755 ; 93.6 \%$ completion rate) or social-networking sites $(n=313$; $68.5 \%$ completion rate; $61.6 \%$ responded to an ad on Craigslist). A total of 1,068 participants completed the survey $(84.5 \%$ of those who started the survey). Students from SFSU participating in the experiment were compensated with course credit. Adults recruited from social-networking sites were entered into a raffle for a chance to win one of ten $\$ 25$ gift cards. All participants took the survey at a computer of their choosing and at their own time. The survey consisted of the SWLS, the SHS, the PANAS-X, and Saucier's (1994) 40-item Mini-Marker Scale. Participants from SFSU were older than average college age $(M=24.73$ years, $S D=10.86)$, with more females $(72 \%)$ participating than males. The SFSU sample was racially diverse, with $29.1 \%$ reporting themselves as being Caucasian, $30.7 \%$ as Asian American, $17.5 \%$ as Hispanic, $13.6 \%$ as multiracial, $4.7 \%$ as African American, 3.6\% as South Asian/ Indian subcontinent, and $0.7 \%$ as "other." Participants from the social-networking sites were older than the college sample $(M=$ 35.55 years, $S D=14.14)$ with more females $(72 \%)$ participating than males. The Web-recruited sample showed less racial diversity, with $64.5 \%$ reporting themselves as being Caucasian, $10.3 \%$ as Asian American, 9.7\% as Hispanic, 7.7\% as multiracial, 5.8\% as African American, and $1.3 \%$ as South Asian/Indian subcontinent. Although the two groups had a similar gender breakdown, those from the Web-recruited sites were, as can be expected, older and more likely to be Caucasian.

\section{Measures}

Life satisfaction. The SWLS (Diener et al., 1985) is a 5-item scale of global life satisfaction. Participants rated the degree to which they agreed with each item $(1=$ strongly disagree; $7=$ strongly agree).

Positive and negative affect. The PANAS-X (Watson \& Clark, 1994) was used to measure state affect. Participants were asked to "indicate to what extent you feel this way right now" for a series of affect descriptors like angry $(1=$ very slightly or not at all; $5=$ extremely).

Happiness. The SHS (Lyubomirsky \& Lepper, 1999) is a 4-item scale of global happiness. Participants rated the degree to which they agreed with each item $(1=$ strongly disagree; $7=$ strongly agree $)$.

Personality traits. The BFI (John et al., 1991) used in Experiment 1 is a 44-item scale used to measure an individual's personality on five personality traits, including extraversion, agreeableness, openness, conscientiousness, and neuroticism. Individuals are asked to rate how much they agree or disagree with each statement $(1=$ disagree strongly; $5=$ agree strongly). In Experiment 3, we utilized Saucier's (1994) 40-item Mini-Marker Scale, developed as a shorter version of Goldberg's adjective markers measure but used similarly to measure the personality traits on the BFI. Individuals are asked to rate the degree to which each item is an accurate descriptor $(1=$ extremely inaccurate; $9=$ extremely accurate).

Demographics. The demographic questions gathered information regarding age, gender, and race or ethnicity.

\section{Testing Equivalence for Each Scale}

We used the same criteria for equivalence that were suggested by Tabachnick and Fidell (1989): The same number of factors should account for about the same amount of variance in the construct, the same items should load on the same factors, and the relationships between factors should be the same. To examine equivalence of factor structure for each measure, therefore, we conducted a principal components analysis (PCA) and extracted the number of factors expected by past research (e.g., SWLS is a single-factor solution). To measure the degree to which factor loadings are similar, Tabachnick and Fidell suggest computing the correlation between the two sets of independent loadings. To examine for equivalence of reliability, we compared the reliability coefficient (Cronbach's alpha) and tested for significant differences using either the Feldt (1969) test for the larger samples or the Fisher-Bonett test (Kim \& Feldt, 2008) for the smaller samples. To demonstrate convergent validity across different survey administration methods (PP, CB, and Internet), we compared the predictive relationships of different SWB outcomes (e.g., the robust finding that extraversion is positively correlated with positive affect) and tested for significant differences between independent 
Table 1

Factor Loadings When Testing the Satisfaction With Life Scale for Equivalence Across Different Modes of Administration and Sample Types

\begin{tabular}{|c|c|c|c|c|c|c|}
\hline \multirow[b]{2}{*}{ Items } & \multicolumn{2}{|c|}{ Experiment 1} & \multicolumn{2}{|c|}{ Experiment 2} & \multicolumn{2}{|c|}{ Experiment 3} \\
\hline & $\begin{array}{c}\text { Computer } \\
\text { Based }\end{array}$ & Internet & $\begin{array}{l}\text { Paper and } \\
\text { Pencil }\end{array}$ & Internet & $\begin{array}{l}\text { Internet } \\
\text { (College) }\end{array}$ & $\begin{array}{c}\text { Internet } \\
\text { (Web-Recruited) }\end{array}$ \\
\hline In most ways my life is close to my ideal. & .81 & .87 & .82 & .88 & .84 & .91 \\
\hline The conditions of my life are excellent. & .81 & .88 & .80 & .82 & .82 & .89 \\
\hline I am satisfied with my life. & .83 & .87 & .86 & .91 & .89 & .91 \\
\hline So far I have gotten the important things I want in life. & .78 & .83 & .76 & .76 & .80 & .83 \\
\hline If I could live my life over, I would change almost nothing. & .71 & .58 & .64 & .62 & .72 & .74 \\
\hline Mean & $4.91^{*}$ & $4.91^{*}$ & $4.85^{*}$ & $4.63^{*}$ & $4.53^{*}$ & $4.31^{\dagger}$ \\
\hline Standard deviation & $1.18^{*}$ & $1.20^{*}$ & $1.15^{*}$ & $1.17^{*}$ & $1.27^{\dagger}$ & $1.48^{*}$ \\
\hline Cronbach's alpha & $.78^{*}$ & $.84^{*}$ & $.82^{*}$ & $.86^{*}$ & $.87^{\dagger}$ & $.91^{*}$ \\
\hline
\end{tabular}

Note-The correlation of loadings was .96 in Experiment 1, .99 in Experiment 2, and .94 in Experiment 3. The factor loadings were compared by computing the correlation of the loadings (see Tabachnick \& Fidell, 1989). Mean differences were compared by computing an independent samples $t$ test. Differences in standard deviations were tested with a Levene's test for equal variance. Differences in reliability coefficients were tested using the Feldt (1969) test for larger samples and using the Fisher-Bonett test (Kim \& Feldt, 2008) for smaller samples. *Means, standard deviations, or alpha coefficients within survey did not differ significantly $(p>.05)$, on the basis of the appropriate inferential test. $\dagger$ Means, standard deviations, or alpha coefficients within survey differed significantly.

correlation coefficients. To examine generalizability, we compared the factor structure, internal consistency, and correlational patterns (convergent validity) between college students from SFSU who completed a survey posted on the Internet for class credit and adults who completed the same Internet survey posted on different socialnetworking Web sites.

\section{RESULTS}

\section{Testing Equivalence of the SWLS}

We first examined the factor structure of the SWLS by conducting a PCA separately for each condition within each experiment (see Table 1). We extracted a single factor for each group, because past work has demonstrated that the SWLS forms a single-factor solution (see Diener et al., 1985). Across all three experiments, the factor loadings were nearly identical-supported by the near-perfect correlation of loadings within each experiment. Examining the means, standard deviations, and reliability coefficients, there were no significant differences when comparing among college students who took the SWLS in the PP condition, those who took it in the $\mathrm{CB}$ condition, and those who took it in the Internet condition (see Table 1, Experiments 1 and 2). However, the much larger sample size in Experiment 3 allowed for detection of significant, though small, differences in means, standard deviations, and reliability coefficients. The adults who completed the Internet version of the SWLS scored lower on the scales, had more variance in their responses, and were more internally consistent.

To test the validity of the SWLS when administered as a CB survey versus as an Internet survey, we examined the robust findings that the BFI personality traits predict SWLS scores. Steel, Schmidt, and Shultz (2008) demonstrated in their meta-analysis that neuroticism is the best (negative) predictor of life satisfaction, followed by extraversion (which has a positive association with life satisfaction). In Experiment 1, the relationships between neuroticism and the SWLS were of similar magnitude for the $\mathrm{CB}[r(97)=-.50, p<.001]$ and Internet $[r(93)=$
$-.45, p<.001]$ conditions and were not significantly different $(Z=0.44, p=.66)$. Also, the relationships between extraversion and the SWLS were in the same direction for the $\mathrm{CB}[r(97)=.42, p<.001]$ and Internet $[r(93)=.25$, $p<.02]$ conditions and were not significantly different $(Z=1.32, p=.19)$. In Experiment 3, the same patterns emerged. The relationships between neuroticism and the SWLS were of near-identical magnitude for the college $[r(772)=-.29, p<.001]$ and Web-recruited $[r(341)=$ $-.29, p<.001]$ samples and were not significantly different $(Z=0.05, p=.96)$. Also, the relationships between extraversion and the SWLS were of similar magnitude for the college $[r(772)=.27, p<.001]$ and Web-recruited $[r(341)=.29, p<.02]$ samples and were not significantly different $(Z=0.27, p=.79)$.

\section{Testing Equivalence of the PANAS-X}

We examined the factor structure of the PANAS-X by conducting a PCA within each condition for Experiments 1 and 3 (see Table 2). For each group, we extracted two separate factors for positive affect (PA) and negative affect (NA) (see Watson \& Clark, 1994). We used a direct oblimin rotation for the PANAS-X, because it was expected to be a two-factor solution with slightly correlated factors. The factor loadings demonstrated the expected two-factor solution across modes (CB vs. Internet) and samples (college vs. Web-recruited). All the positiveemotion items loaded onto a signal factor, and none of the positive-emotion items had loadings greater than .30 on the second (NA) factor. The same pattern was observed for the negative-emotion items. In Experiment 1, the equivalence across modes for PA was demonstrated by the strong, positive correlation of loadings; however, the correlation of the loading for NA was much weaker in the CB condition than in the Internet condition in Experiment 1. Although the loadings were all positive and above .30, jittery and guilty loaded more strongly on the CB-NA construct than on the Internet-NA construct. When comparing the means, standard deviations, and reliability coefficients in 
Table 2

Factor Loadings When Testing the Positive and Negative Affect Schedule for Equivalence Across Different Modes of Administration and Sample Types

\begin{tabular}{|c|c|c|c|c|c|c|c|c|}
\hline \multirow[b]{4}{*}{ Items } & \multirow{2}{*}{\multicolumn{4}{|c|}{ Experiment 1}} & \multicolumn{4}{|c|}{ Experiment 3-Internet Survey } \\
\hline & & & & & \multicolumn{2}{|c|}{ Positive Affect } & \multicolumn{2}{|c|}{ Negative Affect } \\
\hline & \multicolumn{2}{|c|}{ Positive Affect } & \multicolumn{2}{|c|}{ Negative Affect } & \multirow[b]{2}{*}{ College } & \multirow{2}{*}{$\begin{array}{c}\text { Web- } \\
\text { Recruited }\end{array}$} & \multirow[b]{2}{*}{ College } & \multirow{2}{*}{$\begin{array}{c}\text { Web- } \\
\text { Recruited }\end{array}$} \\
\hline & $\mathrm{CB}$ & Internet & $\mathrm{CB}$ & Internet & & & & \\
\hline Active & .74 & .75 & - & - & .72 & .75 & - & - \\
\hline Attentive & .58 & .61 & - & - & .59 & .70 & - & - \\
\hline Alert & .56 & .72 & - & - & .68 & .74 & - & - \\
\hline Determined & .73 & .75 & - & - & .74 & .81 & - & - \\
\hline Enthusiastic & .87 & .86 & - & - & .80 & .87 & - & - \\
\hline Excited & .81 & .72 & - & - & .72 & .79 & - & - \\
\hline Inspired & .76 & .76 & _- & _- & .77 & .80 & _- & _- \\
\hline Interested & .75 & .78 & - & - & .76 & .78 & - & - \\
\hline Proud & .79 & .74 & - & - & .75 & .74 & - & - \\
\hline Strong & .72 & .68 & - & - & .67 & .74 & - & - \\
\hline Afraid & - & - & .69 & .82 & - & - & .71 & .78 \\
\hline Scared & - & - & .80 & .79 & - & - & .77 & .84 \\
\hline Nervous & - & - & .78 & .67 & - & - & .73 & .77 \\
\hline Jittery & - & - & .69 & .55 & - & - & .55 & .72 \\
\hline Irritable & - & - & .56 & .68 & - & - & .70 & .73 \\
\hline Hostile & - & - & .72 & .66 & - & - & .53 & .62 \\
\hline Guilty & - & - & .78 & .61 & - & - & .66 & .68 \\
\hline Ashamed & - & - & .68 & .63 & - & - & .66 & .79 \\
\hline Upset & - & - & .73 & .83 & - & - & .70 & .79 \\
\hline Distressed & - & - & .56 & .63 & - & - & .71 & .79 \\
\hline Mean & $3.00^{*}$ & $3.06^{*}$ & $1.82^{*}$ & $1.70^{*}$ & $3.02^{*}$ & $3.00^{*}$ & $1.78^{*}$ & $1.85^{*}$ \\
\hline Standard deviation & $0.88^{*}$ & $0.85^{*}$ & $0.78^{*}$ & $0.68^{*}$ & $0.85^{*}$ & $0.91^{*}$ & $0.71^{\dagger}$ & $0.81^{*}$ \\
\hline Cronbach's alpha & $.90^{*}$ & $.90^{*}$ & $.88^{*}$ & $.88^{*}$ & $.90^{\dagger}$ & $.92^{*}$ & $.86^{\dagger}$ & $.91^{*}$ \\
\hline
\end{tabular}

Note - CB, computer based. A dash $(-)$ indicates that factor loading is $<.30$. In Experiment 1, the correlation of loadings between the CB sample and the Internet sample was .72 for positive affect and .23 for negative affect. In Experiment 3, the correlation of loadings between the college sample and the Web-recruited sample was .82 for positive affect and .80 for negative affect. *Means, standard deviations, or alpha coefficients within survey did not differ significantly ( $p>.05$ ), on the basis of the appropriate inferential test. †Means, standard deviations, or alpha coefficients within survey differed significantly.

Experiment 1, there were no significant differences between the $\mathrm{CB}$ and Internet conditions. In Experiment 3, the equivalence of the factors across samples for both PA and NA were demonstrated by the strong, positive correlation of loadings. In Experiment 3, we detected significant, though small, differences in standard deviations and reliability coefficients. The adults who completed the Internet version of the PANAS-X had more variance in their responses and were more internally consistent.

PA and NA have been consistently correlated with each of the BFI personality factors (DeNeve \& Cooper, 1998); however, extraversion emerges as the strongest predictor of PA, and neuroticism emerges as the strongest predictor of NA (McNeil \& Fleeson, 2006; Schimmack, Oishi, Furr, \& Funder, 2004; Vittersø \& Nilsen, 2002). To test the validity of the PANAS-X when administered via the Internet, the correlates between extraversion and PA as well as neuroticism and NA were examined. In Experiment 1, the relationships between extraversion and PA were of similar magnitude for both conditions [CB, $r(97)=.42$, $p<.001$; Internet, $r(93)=.38, p<.001]$ and were not significantly different $(Z=0.33, p=.77)$. Also, the relationships between neuroticism and NA were of similar magnitude for the $\mathrm{CB}[r(97)=.38, p<.001]$ and Internet $[r(93)=.47, p<.02]$ conditions and not significantly different $(Z=0.71, p=.45)$. As was true for the SWLS, in Experiment 3, there were no substantial differences between college and Web-recruited samples in correlational patterns. The relationships between extraversion and PA were of similar magnitude for the college $[r(771)=.33$, $p<.001]$ and Web-recruited $[r(341)=.39, p<.001]$ groups and were not significantly different $(Z=1.05, p=$ .29). Also, the relationships between neuroticism and NA were of similar magnitude for the college $[r(772)=.37$, $p<.001]$ and Web-recruited $[r(341)=.46, p<.001]$ samples and were moderately significantly different $(Z=$ $1.67, p=.09$ ).

\section{Testing Equivalence of the SHS}

As we did for the SWLS and the PANAS-X, we examined the factor structure of the SHS by conducting a PCA separately for each condition within Experiments 2 and 3 (see Table 3). For each group, we extracted a single-factor solution, as suggested by previous research (Lyubomirsky \& Lepper, 1999). In Experiment 2, the first three items had nearly identical factor loadings; however, the last item (the only reverse-coded item) had a much lower loading in the Internet condition. In Experiment 3, the first three items again had near identical loadings, and the loading for the last item was lower than that for the other three items; however, the difference in factor loadings between the college and Web-recruited samples was not drastic. For both 
Table 3

Factor Loadings When Testing the Subjective Happiness Scale for Equivalence Across Different Modes of Administration and Sample Types

\begin{tabular}{|c|c|c|c|c|}
\hline \multirow[b]{2}{*}{ Items } & \multicolumn{2}{|c|}{ Experiment 2} & \multicolumn{2}{|c|}{ Experiment 3} \\
\hline & $\begin{array}{l}\text { Paper and } \\
\text { Pencil }\end{array}$ & Internet & $\begin{array}{c}\text { Internet } \\
\text { (College) }\end{array}$ & $\begin{array}{c}\text { Internet } \\
\text { (Web-Recruited) }\end{array}$ \\
\hline In general I consider myself a very happy person. & .90 & .87 & .90 & .92 \\
\hline Compared to most of my peers, I consider myself more happy. & .89 & .87 & .89 & .91 \\
\hline $\begin{array}{l}\text { Some people are generally very happy. They enjoy life regard- } \\
\text { less of what is going on, getting the most out of everything. } \\
\text { To what extent does this characterization describe you? }\end{array}$ & .87 & .88 & .87 & .91 \\
\hline $\begin{array}{l}\text { Some people are generally not very happy. Although they are } \\
\text { not depressed, they never seem as happy as they might be. To } \\
\text { what extent does this characterization describe you?* }\end{array}$ & .74 & .49 & .66 & .60 \\
\hline $\begin{array}{l}\text { Mean } \\
\text { Standard deviation } \\
\text { Cronbach's alpha }\end{array}$ & $\begin{array}{r}5.04^{\dagger} \\
1.10^{\dagger} \\
.87^{\dagger}\end{array}$ & $\begin{array}{r}5.02^{\dagger} \\
1.02^{\dagger} \\
.79^{\dagger \dagger}\end{array}$ & $\begin{array}{c}4.90^{\dagger} \\
1.12^{\dagger \dagger} \\
.84^{\dagger}\end{array}$ & $\begin{array}{c}4.74^{\dagger \dagger} \\
1.33^{\dagger} \\
.85^{\dagger}\end{array}$ \\
\hline
\end{tabular}

Note-The coefficient of congruence for Experiment 2 was .98, and the coefficient of congruence for Experiment 3 was 99. "This item is reverse coded. †Means, standard deviations, or alpha coefficients within survey did not differ significantly $(p>.05)$, on the basis of the appropriate inferential test. ${ }^{\dagger}$ Means, standard deviations, or alpha coefficients within survey differed significantly.

Experiment 2 and Experiment 3, the equivalence across modes and samples was demonstrated by the strong, positive correlation of loadings. When comparing the means, standard deviations, and reliability coefficients, many of the same patterns emerged as were observed when examining the SWLS. There were no significant differences in means or standard deviations when comparing the college students who took the SHS in the PP condition with those who took it in the Internet condition; however, the reliability was significantly higher when students took the PP version because of the higher loading of the fourth item. For Experiment 3, there were significant differences in the mean scores (the college sample was happier than the Webrecruited sample) and in the variance (the Web-recruited sample was more variable than the college sample). Importantly, there was no significant difference in reliability.

To test the validity of the SHS when administered over the Internet, we examined the correlations between the SHS and life satisfaction, PA, NA, extraversion, and neuroticism. Lyubomirsky and Lepper (1999) demonstrated that the SHS is positively correlated with life satisfaction, $\mathrm{PA}$, and extraversion but negatively correlated with NA and neuroticism. In Experiment 2, the relationships between the SHS and the SWLS were of similar magnitude for the PP $[r(97)=.47, p<.001]$ and Internet $[r(75)=$ $.64, p<.001]$ conditions and were moderately significantly different $(Z=1.64, p=.10)$. With more surveys in Experiment 3, we examined more correlations (see Table 4) across college and Web-recruited samples. What stands out is the consistency in the pattern of correlations. The relationship between the correlations for the college sample and those for the Web-recruited sample demonstrates a near-perfect consistency $[r(13)=.99, p<.001]$. Furthermore, there were only two significant differences between the independent correlations, and both of the correlations were stronger for the Web-recruited sample: The SHS-PA correlation was stronger for the Web-recruited sample $(Z=3.53, p<.001)$, and the SWLS-PA correlation was stronger for the Web-recruited sample $(Z=2.12$, $p=.03)$.

Table 4

Comparing the Correlations Between a College Internet Sample $(n=773)$ and a Web-Recruited Internet Sample $(n=343)$

\begin{tabular}{clrcccc}
\hline \multicolumn{1}{c}{ Sample } & Construct & SHS & SWLS & PA & NA & Extraversion \\
\hline College Internet & SWLS & $.61^{* *}$ & - & - & - & - \\
& PA & $.42^{* *}$ & $.30^{* *}$ & - & - & - \\
& NA & $-.32^{* *}$ & $-.34^{* *}$ & -.02 & - & - \\
Web-recruited adult Internet & Extraversion & $.44^{* *}$ & $.27^{* *}$ & $.33^{* *}$ & $-.16^{* *}$ & - \\
& Neuroticism & $-.45^{* *}$ & $-.29^{* *}$ & $-.21^{* *}$ & $.37^{* *}$ & $-.17^{* *}$ \\
& SWLS & $.65^{* *}$ & - & - & - & - \\
& PA & $.59^{* *}$ & $.42^{* *}$ & - & - & - \\
& NA & $-.35^{* *}$ & $-.28^{* *}$ & -.05 & - & - \\
& Extraversion & $.43^{* *}$ & $.29^{* *}$ & $.33^{* *}$ & $-.14^{* *}$ & - \\
& Neuroticism & $-.44^{* *}$ & $-.29^{* *}$ & $-.28^{* *}$ & $.46^{* *}$ & $-.19^{* *}$ \\
\hline
\end{tabular}

Note-SHS, Subjective Happiness Scale; SWLS, Satisfaction With Life Scale; PA, positive affect; NA, negative affect. There were only two significant differences between the independent correlations: The SHS-PA correlation was stronger for the Web-recruited sample $(Z=3.53, p<.001)$, and the SWLS-PA correlation was stronger for the Web-recruited sample $(Z=2.12, p=.03) .{ }^{*} p<.05 .{ }^{* *} p<.01$. 


\section{DISCUSSION}

This study compared the quality of data collected using PP, CB, and Internet methods for three of the most frequently used measures of SWB - SWLS, PANAS-X, and SHS. We began by comparing these results with past literature. First, the results of this study replicated the findings by Buchanan and Smith (1999) and Lonsdale et al. (2006), who both demonstrated that the factor structure of the surveys they examined on the Internet were similar to published norms and across different modes. Second, by examining the PANAS-X (a multidimensional scale), this study demonstrated that a multidimensional scale administered over the Internet is capable of producing data equivalent to those of a PP or CB survey. This result corroborated those reported by Hewson and Charlton (2005) demonstrating that an Internet-based multidimensional scale is capable of producing data equivalent to those of a PP test. Third, although some studies have found that participants are more likely to divulge personal or private information (e.g., NA, suicidal tendencies) on CB or Internet surveys than on PP surveys (Buchanan, 2002; Davis, 1999), we did not find any differences in reports of life satisfaction, PA or NA, or happiness when comparing PP, CB, and Internet versions of these surveys.

Taken as a whole, these results provide evidence that these three SWB measures perform similarly when administered as PP, CB, or Internet surveys and when administered to college students or adults recruited over the Internet. Across the three experiments, the results indicate that the CB and Internet surveys had similar means, standard deviations, reliabilities, and factor structures to those of PP surveys, and for both college and Web-recruited samples; thus, this study supports the reliability, validity, and generalizability of the Internet format of the SWLS, PANAS-X, and SHS. As described below, there are a few differences overall within the three experiments that we believe may be informative for future research.

Internet-accessed samples had a higher dropout rate. As demonstrated by Experiment 3, the Internet survey that recruited adults from different social-networking Web sites, there were significantly more participants who began the experiment but did not finish $(31.5 \%)$ than among the college students completing the Internet survey who received course credit (only 6.4\%). Given these results, it seems reasonable to conclude that receiving course credit is more motivating to college students asked to take and complete a survey than is a 1 in 100 chance of winning a raffle worth $\$ 25$ to an adult sample. Although Lonsdale et al. (2006) found no significant differences between response rates on the Athlete Burnout Questionnaire, Denscombe (2008) argued that three of the major disadvantages of the Internet for research are coverage error, sampling error, and nonresponse error. Our findings also replicated work by Brečko and Carstens (2006), who found a significantly higher attrition rate in their Internetbased survey than in their paper survey. They reported that most of their dropouts stopped answering questions (1) when they saw a large matrix of questions or (2) when they got to the demographic sections of the surveys.
In Experiment 3, the largest attrition rate occurred after the second survey-only 10 questions into the survey. After answering the 10th question, $15 \%$ of the sample exited the survey. Similar to Brečko and Carstens (2006), we found that although the completion rate was higher for the PP survey, both methods produced data of comparable quality; thus, rate of attrition appears to affect generalizability but not data quality. In determining the characteristics of participants who did not complete the survey, we found that those who did not finish were no different in life satisfaction, PA or NA, or any of the BFI personality traits; however, those who did not finish were slightly, though significantly, less happy. Given the lack of other predictors, there is a need for more research to understand why individuals do not finish Internet surveys, when they exit, and how to minimize attrition rates.

The possible problem of reverse coding. The three SWB measures used in this study not only are the most widely used scales to assess life satisfaction, emotions and affect, and happiness, but also have simple scoring systems. The SWLS has 5 items - all scored in the same direction. The PANAS-X has 20 emotional descriptive terms, with 10 rather easy-to-identify positive and 10 rather easy-to-identify negative emotional items. The SHS has 4 items and was the only scale used that had a reversecoded item (Some people are generally not very happy. Although they are not depressed, they never seem as happy as they might be. To what extent does this characterization describe you?). For the Internet condition in Experiment 2 , this item loaded rather weakly onto the construct in comparison with the other items. For the one reversecoded item, therefore, the factor loading was much lower than in the PP version. Although this result was not replicated in Experiment 3, we believe that future research should examine the equivalence of PP, CB, and Internet SWB surveys, with a focus on the effect that mode of administration may have on reverse-coded items.

Are unhappy people taking well-being surveys? When there were differences in means, standard deviations, and reliabilities, most of them occurred in Experiment 3-in which the aim was to compare college students with adults recruited online. There were two notable findings in Experiment 3. First, most of the psychometric data indicated that the SWB measures performed better on the Internet for the Web-recruited sample. For example, the Web-recruited sample had the most internally consistent scores for the SWLS and for the PA and NA subscales of the PANAS-X. There was also significantly more variability in the scores for the SWLS, for the PA and NA subscales of the PANAS-X, and for the SHS among the Web-recruited adult sample. As has been discussed in previous research, Internet-based research allows for the recruitment of a wide range of ages and more geographically diverse samples (see Buchanan \& Smith, 1999; Hewson \& Charlton, 2005; Im et al., 2005). This diversity may explain the increased variance for the Web-recruited sample and, ultimately, the increased reliability. Second, the Web-recruited sample also scored lower on the SWLS and the SHS. Could it be that those who take well-being surveys through the Internet are less happy and less satis- 
fied with their lives than is the population as a whole? For example, in comparison with the U.S. adult community that Lyubomirsky and Lepper (1999) sampled, the Internet sample in this study was significantly less happy; compared with adults living in the United States, England, and Australia (see Pavot \& Diener, 1993), this sample of adults was significantly less satisfied with their lives. Even though the Web-recruited sample was more variable and consistent with its answers, therefore, the sample that volunteered for the survey might affect the generalizability of these findings. We suggest that there is a need for more research on why individuals decide to take Internet surveys, with a focus on well-being surveys, and how well these samples generalize.

\section{Conclusion}

Survey research administered through the Internet is increasing because it is easier, is more efficient and cost effective, and can target an adult sample better than PP methods (Nosen \& Woody, 2008) can. And yet concerns about the quality of Internet survey research are still prevalent. With an acknowledgment of all these concerns, most past research has indicated that PP, CB, and Internet studies produce equivalent data; however, the most important concern raised has been that researchers must be cautious not to generalize the validation of one Internet survey to indicate that all surveys will be equivalent when created as Internet surveys. These results, taken as a whole, support the reliability, validity, and generalizability of the Internet format of the SWLS, PANAS-X, and SHS.

\section{AUTHOR NOTE}

Correspondence concerning this article should be addressed to R. T. Howell, Department of Psychology, San Francisco State University, 1600 Holloway Avenue, San Francisco, CA 94132 (e-mail: rhowell@ sfsu.edu).

\section{REFERENCES}

Bech, M., \& Kristensen, M. B. (2009). Differential response rates in postal and Web-based surveys in older respondents. Survey Research Methods, 3, 1-6.

Birnbaum, M. H. (2004). Human research and data collection via the Internet. Annual Review of Psychology, 55, 803-832.

Bliven, B. D., Kaufman, S. E., \& Spertus, J. A. (2001). Electronic collection of health-related quality of life data: Validity, time, benefits, and patient preference. Quality of Life Research, 10, 15-21.

BREČKO, B. N., \& CARSTENS, R. (2006). Online data collection in SITES 2006. Paper versus Web survey-Do they provide comparable results? The Second IEA International Research Conference: Proceedings of the IRC-2006, 2, 261-269.

Buchanan, T. (2002). Online assessment: Desirable or dangerous? Professional Psychology: Research \& Practice, 33, 148-154.

Buchanan, T., Johnson, J. A., \& GoldberG, L. R. (2005). Implementing a five-factor personality inventory for use on the Internet. European Journal of Psychological Assessment, 21, 115-127.

Buchanan, T., \& SMith, J. L. (1999). Using the Internet for psychological research: Personality testing on the World Wide Web. British Journal of Psychology, 90, 125-144.

Carlbring, P., Brunt, S., Bohman, S., Austin, D., Richards, J., Ost, L.-G., \& Andersson, G. (2007). Internet vs. paper and pencil administration of questionnaires commonly used in panic/agoraphobia research. Computers in Human Behavior, 23, 1421-1434.

Chuah, S. C., Drasgow, F., \& Roberts, B. W. (2006). Personality measurement: Does the medium matter? No. Journal of Research in Personality, 40, 359-376.
Cole, M. S., Bedeian, A. G., \& Field, H. S. (2006). The measurement equivalence of Web-based and paper-and-pencil measures of transformational leadership. Organizational Research Methods, 9, 339-368.

DAVIS, R. N. (1999). Web-based administration of a personality questionnaire: Comparison with traditional methods. Behavior Research Methods, Instruments, \& Computers, 31, 572-577.

DeNeve, K. M., \& Cooper, H. (1998). The happy personality: A metaanalysis of 137 personality traits and subjective well-being. Psychological Bulletin, 124, 197-229.

Denscombe, M. (2008). The length of responses to open-ended questions: A comparison of online and paper questionnaires in terms of a mode effect. Social Science Computer Review, 26, 359-368.

Diener, E., Emmons, R. A., Larsen, R. J., \& Griffin, S. (1985). The Satisfaction With Life Scale. Journal of Personality Assessment, 49, 71-75.

Diener, E., \& Seligman, M. E. P. (2004). Beyond money. Toward an economy of well-being. Psychological Science in the Public Interest, $\mathbf{5}, 1-31$.

FELDT, L. S. (1969). A test of the hypothesis that Cronbach's alpha or Kuder-Richardson coefficient twenty is the same for two tests. Psychometrika, 34, 363-373.

Fortson, B. L., Scotti, J. R., Del Ben, K. S., \& Chen, Y.-C. (2006). Reliability and validity of an Internet traumatic stress survey with a college student sample. Journal of Traumatic Stress, 19, 709-720.

George, C. E., LankFord, J. S., \& Wilson, S. E. (1992). The effects of computerized versus paper-and-pencil administration on measures of negative affect. Computers in Human Behavior, 8, 203-209.

Gosling, S. D., Vazire, S., Srivastava, S., \& John, O. P. (2004). Should we trust Web-based studies: A comparative analysis of six preconceptions about Internet questionnaires. American Psychologist, 59, 93-104

Herrero, J., \& Meneses, J. (2006). Short Web-based versions of the perceived stress (PSS) and Center for Epidemiological StudiesDepression (CESD) Scales: A comparison to pencil and paper responses among Internet users. Computers in Human Behavior, 22, 830-846.

Hewson, C., \& Charlton, J. P. (2005). Measuring health beliefs on the Internet: A comparison of paper and Internet administrations of the Multidimensional Health Locus of Control Scale. Behavior Research Methods, 37, 691-702.

Im, E.-O., Chee, W., Bender, M., Cheng, C.-Y., Tsai, H.-M., Kang, N. M., \& LEE, H. (2005). The psychometric properties of pen-andpencil and Internet versions of the Midlife Women's Symptom Index (MSI). International Journal of Nursing Studies, 42, 167-177.

John, O. P., Donahue, E. M., \& Kentle, R. L. (1991). The Big Five inventory -Versions 4a and 54. Berkeley: University of California, Berkeley, Institute of Personality and Social Research.

JoInson, A. (1999). Social desirability, anonymity, and Internet-based questionnaires. Behavior Research Methods, Instruments, \& Computers, 31, 433-438.

KIM, S., \& FELDT, L. S. (2008). A comparison of tests for equality of two or more independent alpha coefficients. Journal of Educational Measurement, 45, 179-193.

KvĚTon, P., JelíneK, M., Klimusová, H., \& VoboŘIL, D. (2007). Data collection on the Internet: Evaluation of Web-based questionnaires. Studia Psychologica, 49, 81-88.

Lonsdale, C., Hodge, K., \& Rose, E. A. (2006). Pixels vs. paper: Comparing online and traditional survey methods in sport psychology. Journal of Sport \& Exercise Psychology, 28, 100-108.

Luthans, F., Avey, J. B., \& Patera, J. L. (2008). Experimental analysis of a Web-based training intervention on the learning and development of positive psychological states. Academy of Management Learning \& Education, 7, 209-221.

LyUbOMIRSKY, S., \& LEPPER, H. S. (1999). A measure of subjective happiness: Preliminary reliability and construct validation. Social Indicators Research, 46, 137-155.

McGraw, K. O., Tew, M. D., \& Williams, J. E. (2000). The integrity of Web-delivered experiments: Can you trust the data? Psychological Science, 11, 502-506.

McNeIL, J. M., \& FleEson, W. (2006). The causal effect of extraversion on positive affect and neuroticism on negative affect: Manipulating state extraversion and state neuroticism in an experimental approach. Journal of Research in Personality, 40, 529-550. 
Nosen, E., \& Woody, S. R. (2008). Online surveys: Effect of research design decision on rates of invalid participation and data credibility. Graduate Student Journal of Psychology, 10, 3-14.

Pavot, W., \& Diener, E. (1993). Review of the Satisfaction With Life Scale. Psychological Assessment, 5, 164-172.

Reimers, S., \& Stewart, N. (2007). Adobe Flash as a medium for online experimentation: A test of reaction time measurement capabilities. Behavior Research Methods, 39, 365-370.

Riva, G., Teruzzi, T., \& ANolli, L. (2003). The use of the Internet in psychological research: Comparison of online and offline questionnaires. CyberPsychology \& Behavior, 6, 73-80.

Rosenfeld, P., Giacalone, R. A., Knouse, S. B., Doherty, L. M., Vicino, S. M., Kantor, J., \& Greaves, J. (1991). Impression management, candor, and microcomputer-based organizational surveys: An individual differences approach. Computers in Human Behavior, 7, 23-32.

RyAN, R. M., \& DECI, E. L. (2001). On happiness and human potentials: A review of research on hedonic and eudaimonic well-being. Annual Review of Psychology, 52, 141-166.

SAUCIER, G. (1994). Mini-Markers: A brief version of Goldberg's unipolar Big-Five markers. Journal of Personality Assessment, 63, 506516.

Schimmack, U., Oishi, S., Furr, R. M., \& Funder, D. C. (2004). Personality and life satisfaction: A facet-level analysis. Personality \& Social Psychology Bulletin, 30, 1062-1075.

SHIH, T.-H., \& FAN, X. (2008). Comparing response rates from Web and mail surveys: A meta-analysis. Field Methods, 20, 249-271.

Steel, P., Schmidt, J., \& Shultz, J. (2008). Refining the relationship between personality and subjective well-being. Psychological Bulletin, 134, 138-161.

Taвachnick, B. G., \& Fidell, L. S. (1989). Using multivariate statistics (2nd ed.). New York: Harper \& Row.
Tseng, H.-M., Macleod, H. A., \& Wright, P. (1997). Computer anxiety and measurement of mood change. Computers in Human Behavior, 13, 305-316.

Vadillo, M. A., BÁrcena, R., \& Matute, H. (2006). The Internet as a research tool in the study of associative learning: An example from overshadowing. Behavioural Processes, 73, 36-40.

Vallejo, M. A., MaÑanes, G., Comeche, M. I., \& Díaz, M. I. (2007). Comparison between administration via Internet and paper-andpencil administration of two clinical instruments: SCL-90-R and GHQ-28. Journal of Behavior Therapy \& Experimental Psychiatry, 39, 201-208

Vereecken, C. A., \& MAes, L. (2006). Comparison of a computeradministered and paper-and-pencil-administered questionnaire on health and lifestyle behaviors. Journal of Adolescent Health, 38, 426432.

VitTERsø, J., \& Nilsen, F. (2002). The conceptual and relational structure of subjective well-being, neuroticism, and extraversion: Once again, neuroticism is the important predictor of happiness. Social Indicators Research, 57, 89-118.

Watson, D., \& Clark, L. A. (1994). The PANAS-X: Manual for the Positive and Negative Affect Schedule-Expanded Form. Iowa City: University of Iowa, Department of Psychology.

Williams, J. E., McGraw, K. O., \& Tew, M. D. (1999). Undergraduate labs and computers: The case for PsychExps. Behavior Research Methods, Instruments, \& Computers, 31, 287-291.

Yu, S.-C., \& Yu, M.-N. (2007). Comparison of Internet-based and paper-based questionnaires in Taiwan using multisample invariance approach. CyberPsychology \& Behavior, 10, 501-507.

(Manuscript received March 24, 2009; revision accepted for publication February 20, 2010.) 